\title{
Non-linear multivariate models for estimating global solar radiation received across five cities in South Africa
}

\author{
Tamara Rosemary Govindasamy ${ }^{1}$, Naven Chetty ${ }^{1,2^{\star}}$ \\ 1. Department of Physics, School of Chemistry and Physics, University of KwaZulu-Natal (Pietermarizburg), \\ South Africa. https://orcid.org/0000-0002-9809-4230 \\ 2. College of Agriculture, Engineering and Science, University of KwaZulu-Natal (Pietermarizburg), South Africa. \\ https://orcid.org/0000-0002-0916-578X)
}

\begin{abstract}
South Africa continues to lag globally in the adoption of renewable energy systems despite a notable decrease in the cost of applicable renewable energy technologies over the past five years. Most applications of potential solar renewable energy systems are currently in various stages of investigation, leaving this readily accessible resource capacity idle. The present study proposes linear and non-linear analysis of multivariate models for estimating global solar radiation (GSR) received across five cities in South Africa. The significance of this study is to provide effective GSR estimation in the application of solar technologies, while increasing their implementation. The dependency of GSR on meteorological variables such as air temperature, relative humidity and relative sunshine duration was evaluated for January 2007 to June 2018 to realise estimation models for each of the study sites. The Hargreaves-Samani and Angstrom-Prescott empirical models served as the basis for single variable analysis of GSR reliance on each meteorological parameter and their relative variations. The results indicated that the proposed non-linear, multivariate equations perform better than the empirical models as well as linear, single variable regression equations. The suggested models are site-specific and demonstrate a strong correlation to historic GSR values with low, acceptable error indicators. It was also recognised that second-and third-order relationships between the clearness index and multiple meteorological variables provide a more accurate description of GSR for most of the cities under study. These methods are cost-effective, easily accessible and appropriate for the evaluation of the feasibility of solar photovoltaic technologies in South Africa.
\end{abstract}

Keywords: renewable energy systems; solar energy; photovoltaic technologies; estimation models

\section{Highlights:}

- Unique non-linear, multivariate estimation models for cities in South Africa

- Estimation models which can be used in photovoltaic technology implementation

Journal of Energy in Southern Africa 30(2): 38-51

DOI: https://dx.doi.org/10.17159/2413-3051/2019/v30i2a6076

Published by the Energy Research Centre, University of Cape Town ISSN: 2413-3051

This work is licensed under a Creative Commons Attribution-ShareAlike 4.0 International Licence https://journals.assaf.org.za/jesa

Sponsored by the Department of Science and Technology

Corresponding author: +27(0)33 2605660

Email: chettyn3@ukzn.ac.za 


\section{Introduction}

South Africa, as one of the world's most coal-dependent countries, has long needed to assess the status of available resources and whether renewables would be a sustainable option for future energy sourcing. The country still trails behind when it comes to discovering and exploring the potential of alternative energy resources, while the world is moving towards greener energy sources to reduce carbon footprint and alleviate the effects of global warming on climatic and environmental conditions.

African countries such as Namibia, Angola and South Africa (especially the Northern Cape) often receive more than double the amount of radiation than countries in the northern hemisphere, e.g. United Kingdom [1]. South Africa is well suited for the harnessing of solar radiation with sunshine being available throughout the year. Disregarding this potential, there are various financial and technical limitations associated with solar energy technologies, which restrict its use to private, off-grid networks. These boundaries need to be resolved to increase the impact and contribution of solar power to the country's energy supply. The present study aims to indicate the amount of underutilised solar potential available in South Africa and to contribute to the knowledge and implementation of solar technologies. With solar radiation data often not being available for most regions locally, most research involves the use of meteorological variables and mathematical relations to investigate the solar potential for sites of interest $[2,3]$. The cost of equipment associated with the measurement of ground solar radiation levels is relatively high, and although it is often the remote locations that receive high levels of solar radiation, there is no solar radiation data for them. Various international studies over the past two decades have led to the development of solar radiation estimation models and time-series weather prediction models using available, measured meteorological factors [2-4]. It is important to obtain accurate models for locations, making it a field of large interest.

This study analysed and enhanced the existing linear models for five major cities in South Africa. Based on the available meteorological conditions provided by local weather stations, it introduced non-linear regression models for these cities and evaluated their efficiency and accuracy over at least ten years. The study also proposed a multivariate model for each of these cities and tested its performance in accordance to single variable models, as well as non-linear variations of them. These proposed models aim to encourage the use of solar radiation estimation models in the procurement of large-scale solar energy technologies. These cost-effective methods and skills are easily accessible and can be included in the assessment of the feasibility of solar photovoltaic (PV) technologies in South Africa.

\section{Background theory}

Physical models that depend on meteorological parameters are viable for estimating solar radiation in regions where solar radiation data is not measured as they have lower computational costs and input data requirements [5]. Although solar radiation data is not extensively measured, the majority of physical models require it for validating and calibrating estimation models. Air temperature, relative humidity and, in most cases, sunshine-duration measurements are easy to conduct and can be obtained from weather stations. The Hargreaves-Samani (H-S) equation (Equation 1) $[4,6,7]$ relates the amount of extra-terrestrial radiation (ETR $=H_{0}$ ) to the difference between the maximum $\left(T_{\max }\right)$ and minimum $\left(T_{\min }\right)$ air temperatures $\left(\Delta T=T_{\max }-T_{\min }\right)$, in order to calculate the amount of global solar radiation $(\mathrm{GSR}=H)$ incident on a horizontal surface $(H)$ [8-14]. The main assumption of this model is that the GSR at a site is responsible for the temperature range [15].

$$
H=H_{o} K_{r}(\Delta T)^{0.5}
$$

where the empirical coefficient $\left(K_{r}\right)=0.16$ for 'interior regions' and $K_{r}=0.19$ for 'coastal regions' [3, $7,16]$, and $\mathrm{H}_{\mathrm{o}}$ is given by Equation 2 [2, 17, 18, 19];

$H_{o}=\frac{24 \times 3.6 \times 10^{-3} I_{s c}}{\pi}\left[1+0.033 \cos \left(\frac{2 \pi D_{n}}{365}\right)\right]\left[\cos \phi \cos \delta \sin \omega_{s}+\omega_{s} \sin \phi \sin \delta\right]$

where $I_{s c}=1367 \mathrm{~W} / \mathrm{m}^{2}$ is known as the solar constant $[2,7,17], D_{\mathrm{n}}$ is the calendar day (1 January (Jan): $D_{n}=1 ; 31$ December (Dec): $\left.D_{n}=365\right)$. The latitude of the site is denoted by $\phi$ (all angles expressed in radians), and $\delta$ is the declination angle given by Equation 3 [20, 21, 22, 23].

$$
\delta=23.45 \frac{\pi}{180} \sin \left[\frac{2 \pi\left(D_{n}+284\right)}{365}\right]
$$

The hour angle $\omega_{s}$ is given by Equation 4 [20, 23, 24].

$$
\omega_{s}=\cos ^{-1}(-\tan \phi \tan \delta)
$$

The ratio of the GSR to ETR $\left(\frac{H}{H_{0}}\right)$ gives a description of the atmosphere's transparency and is called the clearness index, which is described by Equation 5 [25].

$$
K_{T}=\frac{H}{H_{o}}
$$


The Angstrom-Prescott (A-P) equation (Equation 6) can be used to calculate the clearness index from the relative sunshine duration, provided the A$\mathrm{P}$ coefficients for the area are known $[20,22,26$ 29].

$$
K_{T}=\frac{H}{H_{o}}=a+b\left(\frac{S}{S_{o}}\right)
$$

where $\mathrm{a}$ and $\mathrm{b}$ are the A-P coefficients, $S$ is the actual hours of sunshine received; and the day length $\left(S_{o}\right)$ is used to translate time (in hours) between sunrise and sunset $[20,21,23,30,31]$, calculated from Equation 7.

$$
S_{o}=\frac{2 \omega_{S}}{15}
$$

For areas where the A-P coefficients are unknown, using $\mathrm{a}=0.25$ and $\mathrm{b}=0.50$ [32] is prescribed.

\section{Statistical error analysis}

Understanding of the accuracy of analysis and proposed models is quantified in terms of the statistical error analysis. The mean bias error (MBE), Equation 8 , specifies the average deviance of the calculated values from observed values and is an indicator of a model's long-term performance [12, 33]. Positive MBE calculations correspond to an over-estimation, while negative MBEs indicate under-estimation. The root mean square error (RMSE), Equation 13, gives insight into the short-term performance of a correlation. The coefficient of determination $\left(\mathrm{R}^{2}\right)$, Equation 14 , is a measure of the correlation between the dependent variables that are predicted from the independent variables. Low values for all statistical error measures are desired [34]. Previous studies propose that percentage errors between $-10 \%$ and $10 \%$ are acceptable [34, 35]. Statistical analysis reported in the present study was calculated using the errortypes given by Equations 8-14.

Mean bias error (MBE) and mean absolute bias error $(M A B E)$

$$
\begin{aligned}
& M B E=\frac{1}{n} \sum_{i=1}^{n}\left(H_{c, i}-H_{m, i}\right) \\
& M A B E=\frac{1}{n} \sum_{i=1}^{n}\left(\left|H_{c, i}-H_{m, i}\right|\right)
\end{aligned}
$$

Mean percentage error (MPE) and mean absolute percentage error (MAPE)

$$
\begin{aligned}
& M P E=\frac{1}{n} \sum_{i=1}^{n}\left(\frac{H_{c, i}-H_{m, i}}{H_{m, i}}\right) \times 100 \% \\
& M A P E=\frac{1}{n} \sum_{i=1}^{n}\left|\left(\frac{H_{c, i}-H_{m, i}}{H_{m, i}}\right)\right| \times 100 \%
\end{aligned}
$$

Mean absolute relative error (MARE)

$$
M A R E=\frac{1}{n} \sum_{i=1}^{n}\left|\left(\frac{H_{m, i}-H_{C, i}}{H_{m, i}}\right)\right|
$$

Root mean square errors (RMSE)

$$
R M S E=\sqrt{\frac{\sum_{i=1}^{n}\left(H_{c, i}-H_{m, i}\right)^{2}}{n}}
$$

Coefficient of determination $\left(R^{2}\right)$

$$
R^{2}=1-\frac{\sum_{i=1}^{n}\left(H_{m, i}-H_{c, i}\right)^{2}}{\sum_{i=1}^{n}\left(H_{m, i}-H_{m_{a v e}}\right)^{2}}
$$

where $H_{c, i}$ and $H_{m, i}$ are the $i^{\text {th }}$ calculated and measured values of GSR, respectively, and $H_{m_{a v e}}$ is the average of the measured $H$ values.

Further research on the estimation of GSR in South Africa through multiple meteorological variables was completed by Adeala et al., which proposed linear models for the nine provinces in South Africa in terms of relative sunshine, air temperature, wind speed and relative humidity. Following a similar approach, the present study focuses on the regression analysis of these meteorological factors and extends to the non-linear impact of multivariate models which include variations of these parameters. Extensive studies were published to detail the non-linear analysis of GSR estimation models across various countries in the world [37-42].

\section{Experimental technique}

Historic meteorological data was obtained from the South African Weather Service (SAWS) and Agricultural Research Council (ARC) for the study sites. Records of sunshine duration $(S)$, air temperature $\left(\Delta T, T_{\max }\right)$, relative humidity $(R H)$ and solar radiation for January 2007-June 2018 was provided by these independent sources. Analysis of the average monthly GSR incident at each site for the specified period was based on dependence on a single meteorological variable and dependence on multiple meteorological variables, using the H-S and A-P Equations 1 and 6 as the foundation models. Sunshine duration and solar radiation measurements are not undertaken for many locations across South Africa because of the cost of equipment and its maintenance. Historic data from the SAWS and ARC was limited for certain regions, e.g., Pietermaritzburg and Durban, as sunshine duration was not measured for the full period. Measurements were recorded for a few months and then stopped, leading to the study being restricted to the available monthly averages. Values for ETR $\left(H_{o}\right)$ and $S_{o}$ were calculated based on the $\phi$ of each site, using Fortran programs [Operating system: Linux 3.4.6-2.10-desktop x86_64, 
System: OpenSUSE 12.2(x86_64), GNU Fortran Compiler, Version: 4.7-2.1.1-86__64].

South Africa's climate is diverse, because of the wide-ranging landscape and oceanic influence [4345], and is best described by noting the climate experienced in various regions (climate zones). The eastern coastline experiences a semi-arid and mild, sub-tropical climate, while the south-western region is Mediterranean in type. The north-eastern part experiences sub-tropical conditions, while a small region in the north-west is a desert climate zone [44].
Air temperature and rainfall patterns across the various climate zones are influenced by the region's topography, terrain and sea proximity $[43,44]$. Sunshine is received throughout the year, including the winter months (April to September), despite much of the country's rainfall occurring during summer (October to March) [43,44]. Average air temperatures range between 15 and $30{ }^{\circ} \mathrm{C}$ during summer and often exceed $38^{\circ} \mathrm{C}$ [43]. Table 1 shows the geographical specifics for each study site at five cities across various climate zones.

Table 1: Geographical details of study sites.

\begin{tabular}{lcccc}
\hline \multicolumn{1}{c}{ Site } & Province & Latitude $^{\circ}$ south) & Longitude ( ${ }^{\circ}$ east) & Elevation $(\mathrm{m})$ \\
\hline Bloemfontein & Free State & 29.1030 & 26.3263 & 1400 \\
Cape Town & Western Cape & 33.9630 & 18.4194 & 670 \\
Durban & KwaZulu-Natal & 29.9650 & 30.4849 & 670 \\
Johannesburg & Gauteng & 26.1430 & 28.3971 & 1800 \\
Pietermaritzburg & KwaZulu-Natal & 29.6270 & 30.4062 & 750 \\
\hline
\end{tabular}

\section{Results and discussion}

Following a full analysis of single variable dependency of GSR for each of the four variables, $\Delta T, T_{\text {max }}, R H$ and $\frac{S}{S_{o}}$ (relative sunshine duration $=S$ is the actual hours of sunshine received / the day length $S_{o}$ ), the dependency of $\frac{H}{H_{O}}$ on multivariate models was further investigated.

\subsection{Single variable analysis}

Figures 1-10 illustrate the single variable dependence of GSR on air temperature and relative sunshine duration with regard to the H-S and A-P empirical models for each study site.

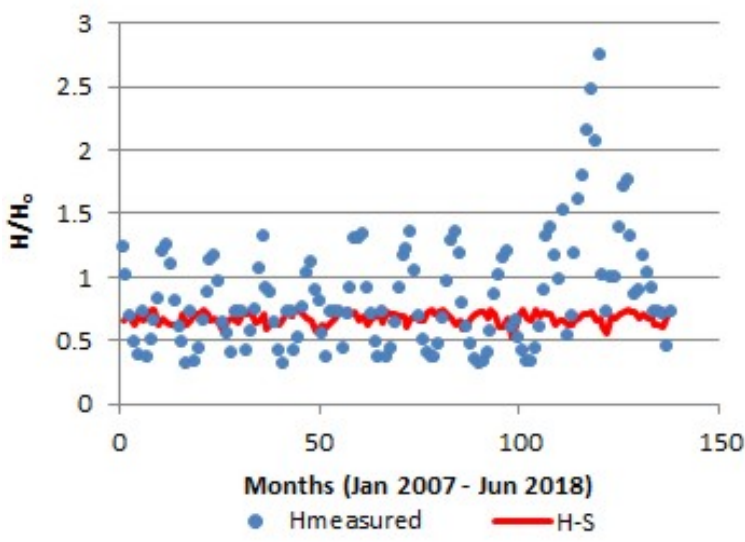

Figure 1: Calculated extra-terrestrial radiationglobal solar radiation ratio $\left(\frac{H}{H_{o}}\right)$ using the $\mathrm{H}-\mathrm{S}$ model for Bloemfontein. Hmeasured represents the observed values of global solar radiation for the period.

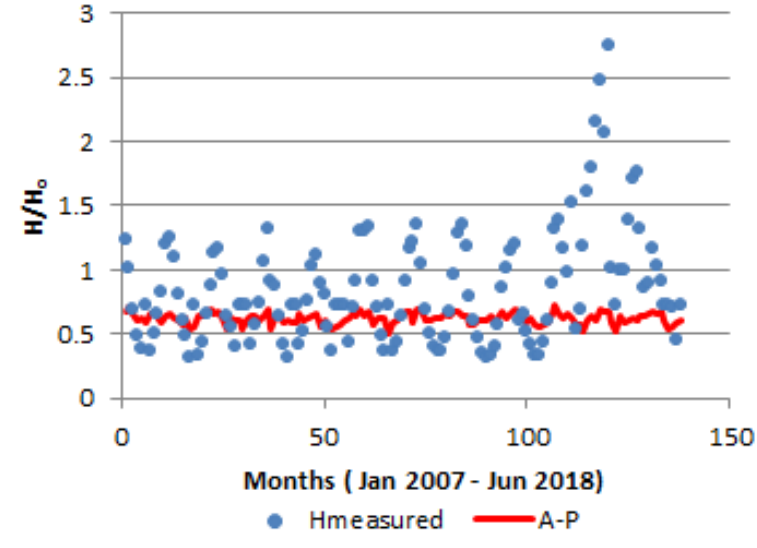

Figure 2: Calculated extra-terrestrial radiationglobal solar radiation ratio $\left(\frac{H}{H}\right)$ using the A-P model for Bloemfontein. Hmeasured represents the observed values of global solar radiation for the period. 


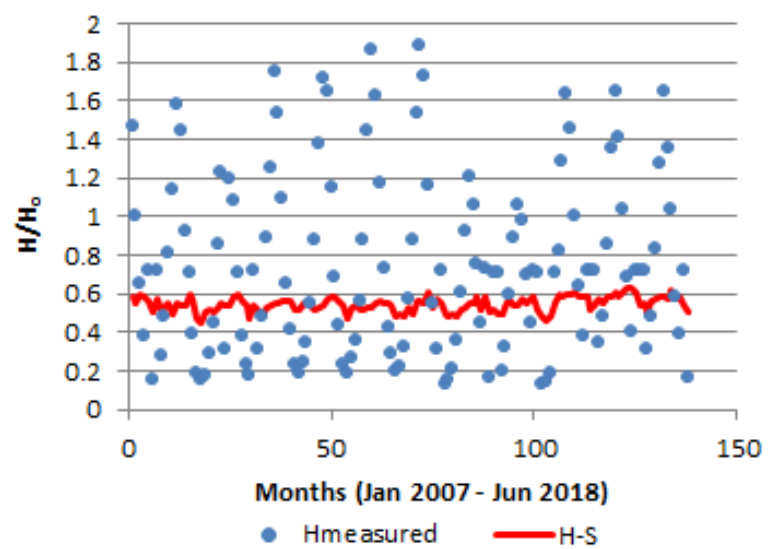

Figure 3: Calculated extra-terrestrial radiationglobal solar radiation ratio $\left(\frac{H}{H_{o}}\right)$ using the H-S model for Cape Town. Hmeasured represents the observed values of global solar radiation for the period.

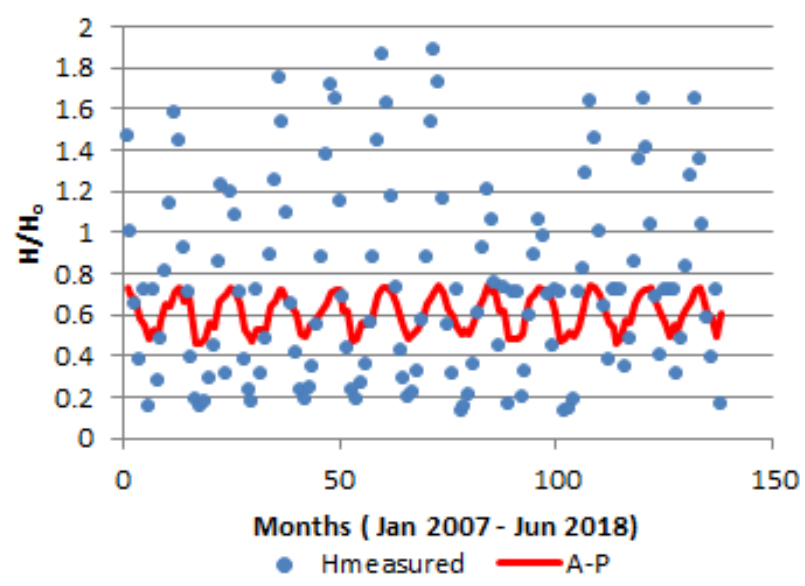

Figure 4: Calculated extra-terrestrial radiationglobal solar radiation ratio $\left(\frac{H}{H_{o}}\right)$ using the A-P model for Cape Town. Hmeasured represents the observed values of global solar radiation for the period.

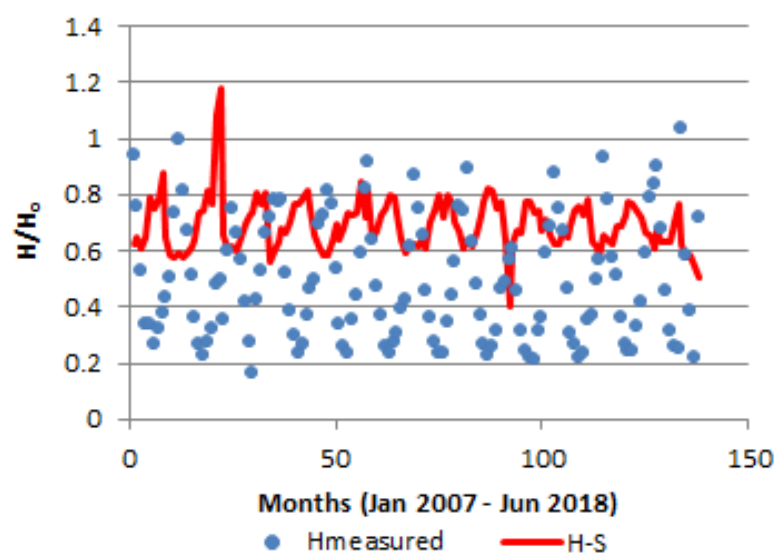

Figure 5: Calculated extra-terrestrial radiationglobal solar radiation ratio $\left(\frac{H}{H_{o}}\right)$ using the H-S model for Durban. Hmeasured represents the observed values of global solar radiation for the period.

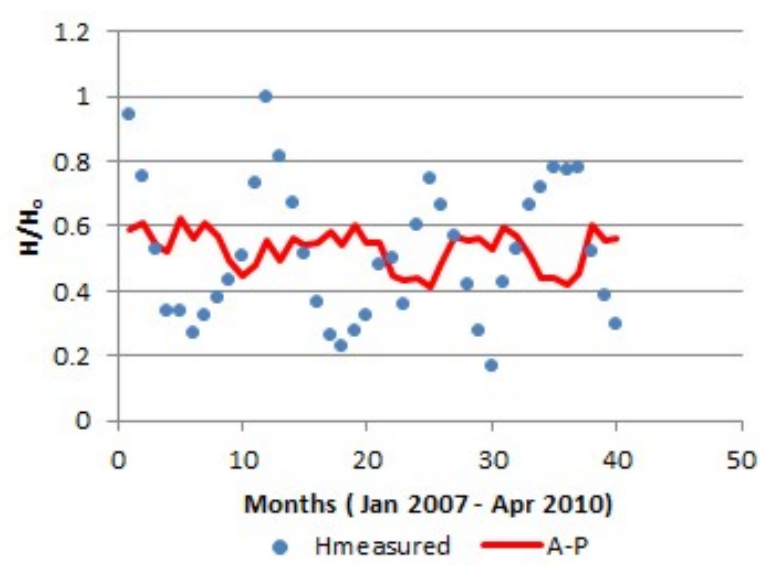

Figure 6: Calculated extra-terrestrial radiationglobal solar radiation ratio $\left(\frac{H}{H_{o}}\right)$ using the A-P model for Durban. Hmeasured represents the observed values of global solar radiation for the period.

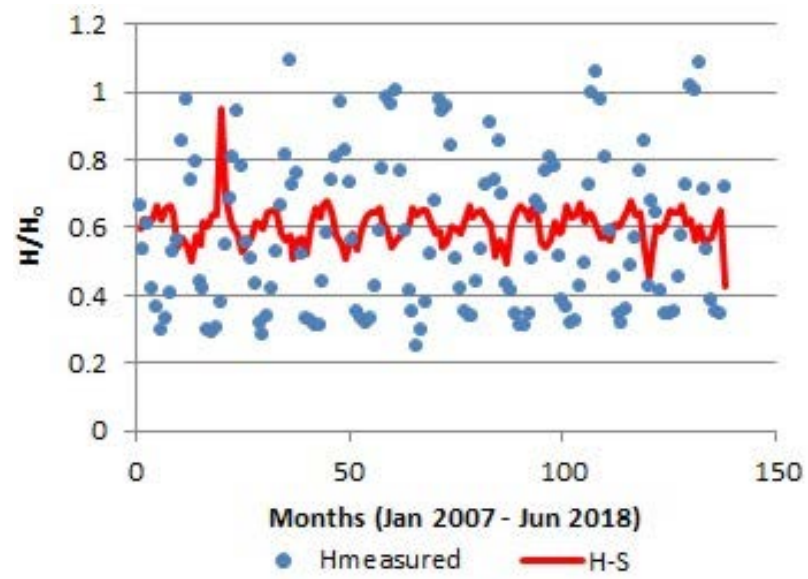

Figure 7: Calculated extra-terrestrial radiationglobal solar radiation ratio $\left(\frac{H}{H_{o}}\right)$ using the $\mathrm{H}-\mathrm{S}$

model for Johannesburg. Hmeasured represents the observed values of global solar radiation for the period.

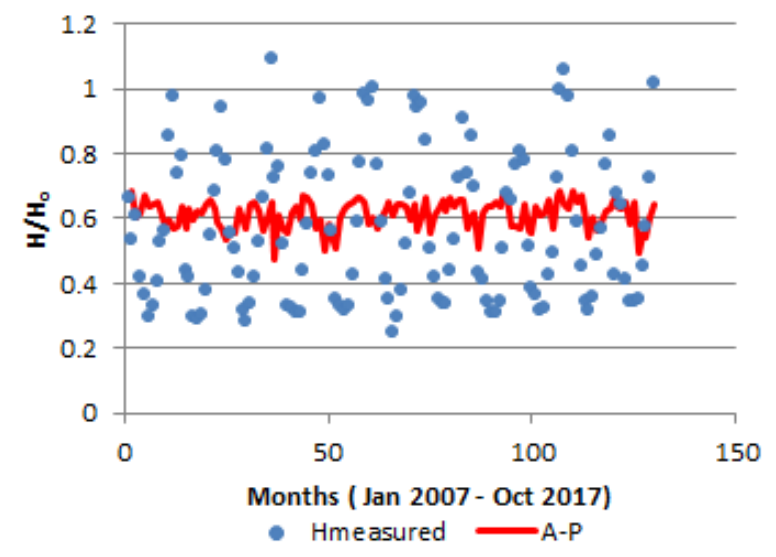

Figure 8: Calculated extra-terrestrial radiationglobal solar radiation ratio $\left(\frac{H}{H_{o}}\right)$ using the A-P

model for Johannesburg. Hmeasured represents the observed values of global solar radiation for the period. 


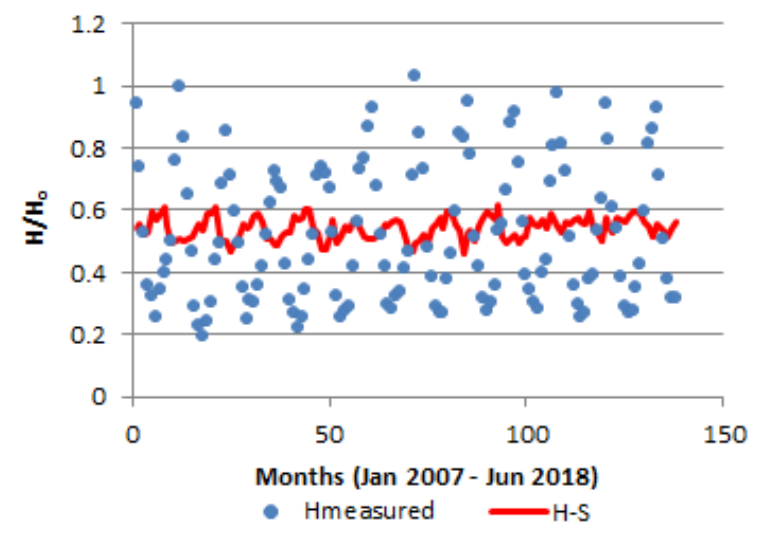

Figure 9: Calculated extra-terrestrial radiationglobal solar radiation ratio $\left(\frac{H}{H_{O}}\right)$ using the $\mathrm{H}-\mathrm{S}$

model for Pietermaritzburg. Hmeasured represents the observed values of global solar radiation for the period.

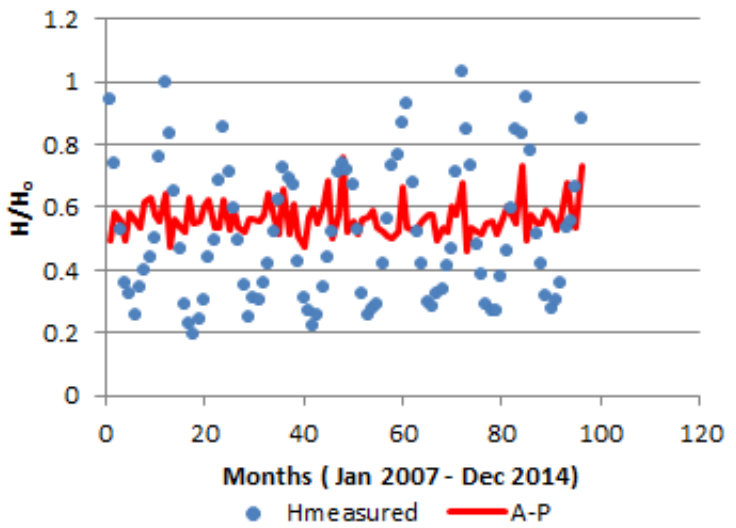

Figure 10: Calculated extra-terrestrial radiationglobal solar radiation ratio $\left(\frac{H}{H_{o}}\right)$ using the A-P model for Pietermaritzburg. Hmeasured represents the observed values of global solar radiation for the period.
From the regression relations obtained for all five sites, $\Delta T$ indicated a weaker correlation to $\frac{H}{H_{o}}$ compared with $T_{\max }$ and $T_{\text {ave }}$. While $R^{2}$ values indicated a low to moderate relationship between temperature and GSR, it was found that estimation models that include additional meteorological variables may perform better. Furthermore, higher order relations (quadratic, cubic and power) showed a better fit to the measured values. The single dependency of measured relative humidity $(R H)$ to GSR was also examined. Relative humidity indicated the weakest relationship to $\frac{H}{H_{O}}$. No established GSR estimation models for this quantity exist, as relative humidity is unable to solely predict GSR. This variable is often used in combination models that do not implicitly account for $\mathrm{RH}$. Sunshine regression equations demonstrated higher correlation values from all three variables. The A-P model performed considerably well and the large number of outliers that were not included by the model can be explained using the universal A-P coefficients. Since established A-P coefficients for the above cities do not exist, the universal coefficients were used: $a=0.25 ; b=0.50$. These coefficients are general and can be used for any site for which the A-P coefficients are unknown. There is merit in obtaining specific A-P coefficients for each site as this enhances the performance of each model based on the site's observed historic sunshine data.

\subsection{Multivariate analysis}

Section 4.1 provided the basis to proceed to include only the variables for which the multivariate analysis showed a stronger correlation. Tables $2-11$ describe the proposed multivariate equations for each site, as well as their associated error indicators.

Table 2: Proposed multivariate equations.

\begin{aligned} & \hline No. Equation \\ & \hline 1$\frac{H}{H_{o}}=-0.053(\Delta T)-0.766\left(\frac{R H}{100}\right)+2.507\left(\frac{S}{S_{o}}\right)+1.930 \\ & 2 \frac{H}{H_{o}}=-0.393(\sqrt{\Delta T})-0.631\left(\frac{R H}{100}\right)+2.623\left(\frac{S}{S_{o}}\right)+0.821 \\ & 3 \frac{H}{H_{o}}=0.040\left(T_{\max }\right)-0.307\left(\frac{R H}{100}\right)+1.151\left(\frac{S}{S_{o}}\right)-0.979 \\ & 4 \frac{H}{H_{o}}=0.394\left(\sqrt{T_{\max }}\right)-0.275\left(\frac{R H}{100}\right)+1.214\left(\frac{S}{S_{o}}\right)-1.999 \\ & 5 \frac{H}{H_{o}}=-0.018(\Delta T)^{2}+0.552(\Delta T)-1.500\left(\frac{R H}{100}\right)^{2}-0.339\left(\frac{R H}{100}\right)+3.752\left(\frac{S}{S_{o}}\right)^{2}-3.546\left(\frac{S}{S_{o}}\right)-2.175 \\ & 6 \frac{H}{H_{o}}=0.002\left(T_{\text {max }}\right)^{2}-0.037\left(T_{\text {max }}\right)-8.813\left(\frac{R H}{100}\right)^{2}-8.107\left(\frac{R H}{100}\right)+3.262\left(\frac{S}{S_{o}}\right)^{2}-4.315\left(\frac{S}{S_{o}}\right)+0.225 \\ & 7 \frac{H}{H_{o}}=0.004(\Delta T)^{3}-0.24(\Delta T)^{2}+4.16(\Delta T)+57.59\left(\frac{R H}{100}\right)^{3}-89.92\left(\frac{R H}{100}\right)^{2}+43.11\left(\frac{R H}{100}\right)-2.65\left(\frac{S}{S_{o}}\right)^{3}+9.31\left(\frac{S}{S_{o}}\right)^{2}-37.29\left(\frac{S}{S_{o}}\right)-27.40 \\ & 8 \frac{H}{H_{o}}=-9.4 \times 10^{-6}\left(T_{\text {max }}\right)^{3}+0.003\left(T_{\text {max }}\right)^{2}-0.06\left(T_{\text {max }}\right)+27.58\left(\frac{R H}{100}\right)^{3}-49.35\left(\frac{R H}{100}\right)^{2}+27.5\left(\frac{R H}{100}\right)+0.14\left(\frac{S}{S_{o}}\right)^{3}+2.13\left(\frac{S}{S_{o}}\right)^{2}-2.99\left(\frac{S}{S_{o}}\right)-2.99 \\ &$\hline No. = number, $\frac{H}{H_{o}}=$ extra-terrestrial radiation-global solar radiation ratio, RH $=$ relative humidity, $\mathrm{T}_{\text {max }}=$ maximum temperature, $\frac{S}{S_{0}}=$ relative sun- \\ & shine duration, $\Delta T=$ temperature difference. \end{aligned}


Table 3: Error indicators for proposed equations.

\begin{tabular}{cccccccc}
\hline Equation & $R M S E$ & $M B E$ & $M A B E$ & $M P E$ & $M A P E$ & $M A R E$ & $R^{2}$ \\
\hline 1 & 0.39594 & 0.05721 & 0.27450 & -9.72644 & 35.91319 & 0.35913 & 0.16348 \\
2 & 0.39734 & 0.05721 & 0.27587 & -9.95571 & 36.22391 & 0.36224 & 0.82761 \\
3 & 0.38825 & 0.05721 & 0.26900 & -6.70049 & 33.71226 & 0.33712 & 0.83507 \\
4 & 0.39012 & 0.05721 & 0.27177 & -6.907291 & 34.27409 & 0.34274 & 0.83348 \\
5 & 0.3249 & 0.05721 & 0.26734 & -8.12844 & 34.65066 & 0.34651 & 0.21935 \\
6 & 0.37720 & 0.05801 & 0.25875 & -5.83789 & 32.12539 & 0.32125 & 0.24080 \\
7 & 0.38037 & 0.05721 & 0.26825 & -7.07460 & 34.50267 & 0.34503 & 0.27990 \\
8 & 0.37725 & 0.05721 & 0.26037 & -6.06718 & 32.31451 & 0.32315 & 0.24115 \\
\hline
\end{tabular}

RMSE = root mean square error, MBE = mean bias error, MABE = mean absolute bias error, MPE $=$ mean percentage error, $\mathrm{MAPE}=$ mean absolute percentage error, $\mathrm{MARE}=$ mean absolute relative error, $\mathrm{R}^{2}=$ coefficient of determination

Table 4: Proposed multivariate equations.

\begin{tabular}{ll}
\hline No. & Equation \\
\hline $1 \frac{H}{H_{o}}=-0.69(\Delta T)-0.179\left(\frac{R H}{100}\right)+2.539\left(\frac{S}{S_{o}}\right)-0.433$ \\
$2 \frac{H}{H_{o}}=-0.395(\sqrt{\Delta T})-0.176\left(\frac{R H}{100}\right)+2.540\left(\frac{S}{S_{o}}\right)+0.124$ \\
$3 \frac{H}{H_{o}}=-0.004\left(T_{\text {max }}\right)-0.165\left(\frac{R H}{100}\right)+2.358\left(\frac{S}{S_{o}}\right)-1.042$ \\
$4 \frac{H}{H_{o}}=-0.394\left(\sqrt{T_{\text {max }}}\right)+0.165\left(\frac{R H}{100}\right)+2.360\left(\frac{S}{S_{o}}\right)-0.962$ \\
$5 \frac{H}{H_{o}}=-0.014(\Delta T)^{2}+0.128(\Delta T)-3.041\left(\frac{R H}{100}\right)^{2}+2.340\left(\frac{R H}{100}\right)+2.812\left(\frac{S}{S_{o}}\right)^{2}-1.305\left(\frac{S}{S_{o}}\right)-0.159$ \\
$6 \frac{H}{H_{o}}=-0.003\left(T_{\text {max }}\right)^{2}+0.094\left(T_{\text {max }}\right)-0.965\left(\frac{R H}{100}\right)^{2}+0.942\left(\frac{R H}{100}\right)+3.549\left(\frac{S}{S_{o}}\right)^{2}-2.060\left(\frac{S}{S_{o}}\right)-0.597$ \\
$7 \frac{H}{H_{o}}=-0.002(\Delta T)^{3}-0.001(\Delta T)^{2}+0.15(\Delta T)+32.35\left(\frac{R H}{100}\right)^{3}-47.97\left(\frac{R H}{100}\right)^{2}+17.94\left(\frac{R H}{100}\right)+1.23\left(\frac{S}{S_{o}}\right)^{3}+0.80\left(\frac{S}{S_{o}}\right)^{2}-0.40\left(\frac{S}{S_{o}}\right)-0.69$ \\
$8 \frac{H}{H_{o}}=4 \times 10^{-4}\left(T_{\text {max }}\right)^{3}-0.03\left(T_{\text {max }}\right)^{2}+0.71\left(T_{\text {max }}\right)+13.33\left(\frac{R H}{100}\right)^{3}-19.66\left(\frac{R H}{100}\right)^{2}+7.52\left(\frac{R H}{100}\right)+2.25\left(\frac{S}{S_{o}}\right)^{3}-0.46\left(\frac{S}{S_{o}}\right)^{2}-0.368\left(\frac{S}{S_{o}}\right)-5.41$ \\
\hline No. $=$ number, $\frac{H}{H_{o}}=$ extra-terrestrial radiation-global solar radiation ratio, RH $=$ relative humidity, $\mathrm{T}_{\max }=$ maximum temperature, $\frac{S}{S_{0}}=$ relative sunshine \\
duration, $\Delta T=$ temperature difference.
\end{tabular}

For Bloemfontein, the first order multivariate equations produced a higher correlation in contrast with the second and third order relations. Low RMSE and MPE indicators, which fall within the accepted range $(-10 \% ; 10 \%)$ were also obtained by the first order relations. Figure 11 shows the performance of the proposed model (Equation 3) amongst the measured values of $\frac{H}{H_{0}}$. The model is adequate in fitting the clearness index values previously measured in Bloemfontein, except for outliers in the last two to three years (months $=110-130$ ). These discrepancies may be a result of the climate change experienced in recent years, or possible data-recording defects.

Tables 4 and 5 show the proposed equations for Cape Town. The $\frac{H}{H_{o}}$ values show a stronger dependency on $T_{\max }$, with the quadratic (Equation 6) and cubic (Equation 8) relations having the highest $R^{2}$ and lowest RMSE values. The MPE indicators are within the accepted range and the MAPEs can be explained by the large number of outliers in the data set. The proposed Equation 8 provides a strong coefficient of determination and low error indicators and hence fits the measured values of GSR well, as indicated in Figure 12. A few underestimations are noticeable but overall the model includes most data points.

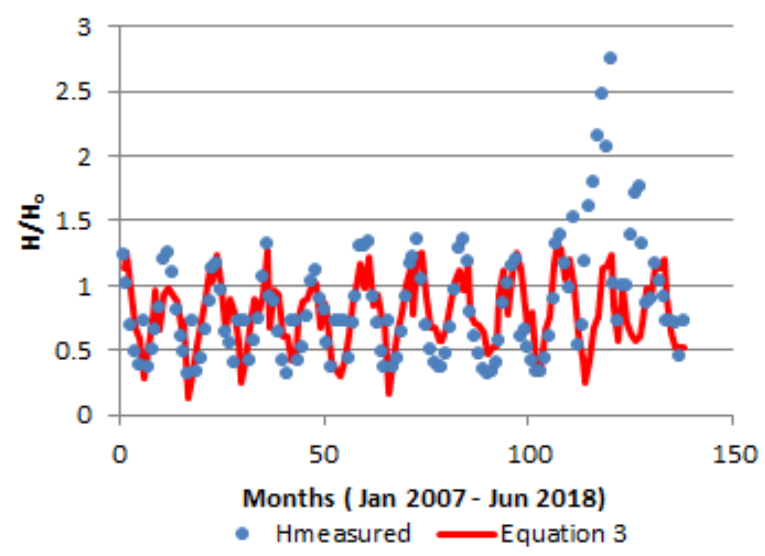

Figure 11: Proposed multivariate model using $T_{\max }$ to estimate $\frac{H}{H_{0}}$ for Bloemfontein, where $T_{\max }$, Hmeasured and $\frac{H}{H_{0}}$ represent the maximum temperature, observed values of global solar radiation and the extra-terrestrial radiationglobal solar radiation ratio respectively. 
Table 5: Error indicators for proposed equations.

\begin{tabular}{cccccccc}
\hline Equation & $R M S E$ & $M B E$ & $M A B E$ & $M P E$ & $M A P E$ & $M A R E$ & $R^{2}$ \\
\hline 1 & 0.29168 & 0.06358 & 0.22174 & 2.34321 & 39.68114 & 0.39681 & 0.57990 \\
2 & 0.30012 & 0.06358 & 0.22187 & 2.20763 & 39.70152 & 0.39702 & 0.88447 \\
3 & 0.29956 & 0.06358 & 0.22425 & 3.95230 & 39.85326 & 0.39853 & 0.88490 \\
4 & 0.29958 & 0.06358 & 0.22424 & 3.93864 & 39.86163 & 0.39862 & 088489 \\
5 & 0.27006 & 0.06358 & 0.19926 & 3.07052 & 31.81996 & 0.31820 & 0.65884 \\
6 & 0.26905 & 0.06358 & 0.19935 & 3.57050 & 31.91099 & 0.31911 & 0.90716 \\
7 & 0.26640 & 0.06358 & 0.19182 & 2.86728 & 29.20680 & 0.29207 & 0.66803 \\
8 & 0.26336 & 0.06358 & 0.19213 & 3.22039 & 28.85694 & 0.28857 & 0.91104 \\
\hline
\end{tabular}

$\mathrm{RMSE}=$ root mean square error, $\mathrm{MBE}=$ mean bias error, $\mathrm{MABE}=$ mean absolute bias error, $\mathrm{MPE}=$ mean percentage error, $\mathrm{MAPE}=$ mean absolute percentage error, $\mathrm{MARE}=$ mean absolute relative error, $\mathrm{R}^{2}=$ coefficient of determination.

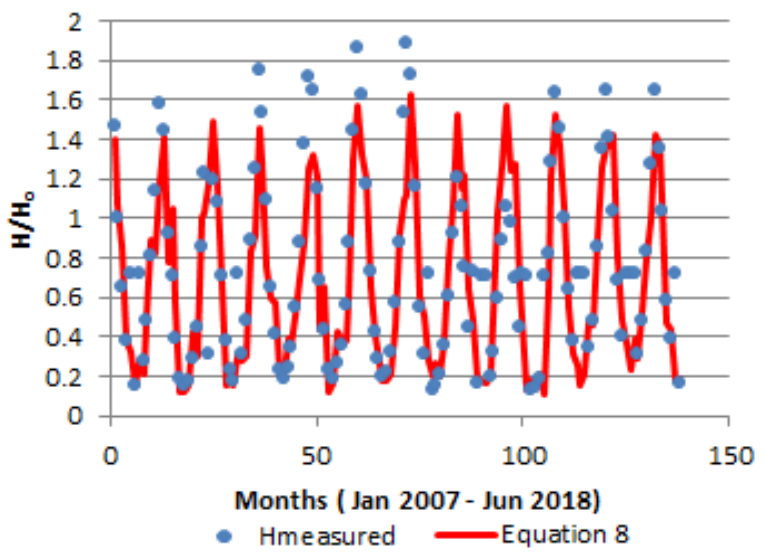

Figure 12: Proposed multivariate model using $\mathrm{T}_{\max }$ to estimate $\frac{H}{H_{0}}$ for Cape Town, where $\mathrm{T}_{\max }$, Hmeasured and $\frac{H}{H}$ represent the maximum temperature, observed values of global solar radiation and the extra-terrestrial radiation-global solar radiation ratio respectively.

Table 6: Proposed multivariate equations.

\begin{tabular}{|c|c|}
\hline No. & Equation \\
\hline 1 & $\frac{H}{H_{o}}=0.002(\Delta T)+2.033\left(\frac{R H}{100}\right)+0.365\left(\frac{S}{S_{o}}\right)-1.201$ \\
\hline 2 & $\frac{H}{H_{o}}=0.020(\sqrt{\Delta T})+2.040\left(\frac{R H}{100}\right)+0.361\left(\frac{S}{S_{o}}\right)+1.242$ \\
\hline 3 & $\frac{H}{H_{o}}=0.008\left(T_{\max }\right)+1.919\left(\frac{R H}{100}\right)+0.413\left(\frac{S}{S_{o}}\right)-1.325$ \\
\hline 4 & $\frac{H}{H_{o}}=0.102\left(\sqrt{T_{\max }}\right)+1.905\left(\frac{R H}{100}\right)+0.416\left(\frac{S}{S_{o}}\right)-1.732$ \\
\hline 5 & $\frac{H}{H_{o}}=4.5 \times 10^{-4}(\Delta T)^{2}-0.019(\Delta T)+7.039\left(\frac{R H}{100}\right)^{2}-8.255\left(\frac{R H}{100}\right)+0.521\left(\frac{S}{S_{o}}\right)^{2}-0.159\left(\frac{S}{S_{o}}\right)-2.844$ \\
\hline 6 & $\frac{H}{H_{o}}=-1.4 \times 10^{-3}\left(T_{\max }\right)^{2}+0.108\left(T_{\max }\right)+13.097\left(\frac{R H}{100}\right)^{2}-16.833\left(\frac{R H}{100}\right)-1.180\left(\frac{S}{S_{o}}\right)^{2}+1.6025\left(\frac{S}{S_{o}}\right)+3.399$ \\
\hline 7 & $\frac{H}{H_{o}}=-9 \times 10^{-5}(\Delta T)^{3}+0.005(\Delta T)^{2}-0.06(\Delta T)-230.5\left(\frac{R H}{100}\right)^{3}+499.5\left(\frac{R H}{100}\right)^{2}-355.4\left(\frac{R H}{100}\right)-9.27\left(\frac{S}{S_{o}}\right)^{3}+13.1\left(\frac{S}{S_{o}}\right)^{2}-5.46\left(\frac{S}{S_{o}}\right)+84.15$ \\
\hline 8 & $\frac{H}{H_{o}}=3.6 \times 10^{-5}\left(T_{\max }\right)^{3}-0.005\left(T_{\max }\right)^{2}+0.23\left(T_{\max }\right)-142.8\left(\frac{R H}{100}\right)^{3}+320.3\left(\frac{R H}{100}\right)^{2}-235.9\left(\frac{R H}{100}\right)-9.18\left(\frac{S}{S_{o}}\right)^{3}+11.78\left(\frac{S}{S_{o}}\right)^{2}-4.19\left(\frac{S}{S_{o}}\right)-54.78$ \\
\hline
\end{tabular}


Table 7: Error indicators for proposed equations.

\begin{tabular}{cccccccc}
\hline Equation & $R M S E$ & $M B E$ & $M A B E$ & $M P E$ & $M A P E$ & $M A R E$ & $R^{2}$ \\
\hline 1 & 0.15789 & 0.02188 & 0.13075 & -7.18984 & 29.15333 & 0.29153 & 0.42176 \\
2 & 0.15792 & 0.02188 & 0.13082 & -7.21693 & 29.20971 & 0.29210 & 0.42153 \\
3 & 0.15648 & 0.02188 & 0.12888 & -6.34183 & 27.92393 & 0.27924 & 0.92113 \\
4 & 0.39039 & 0.02188 & 0.12188 & 3.86583 & -31.31340 & 0.42384 & 0.30871 \\
5 & 0.14688 & 0.02188 & 0.11608 & -6.07546 & 25.32882 & 0.25329 & 0.49962 \\
6 & 0.12589 & 0.02188 & 0.10413 & -2.0700 & 21.34543 & 0.21345 & 0.94895 \\
7 & 0.14598 & 0.02188 & 0.11043 & -4.05942 & 22.36994 & 0.22370 & 0.50567 \\
8 & 0.13117 & 0.02188 & 0.10559 & -1.59414 & 20.55594 & 0.20560 & 0.94458 \\
\hline
\end{tabular}

RMSE = root mean square error, $\mathrm{MBE}=$ mean bias error, $\mathrm{MABE}=$ mean absolute bias error, $\mathrm{MPE}=$ mean percentage error, $\mathrm{MAPE}=$ mean absolute percentage error, $\mathrm{MARE}=$ mean absolute relative error, $\mathrm{R}^{2}=$ coefficient of determination.

First, second and third order equations using $T_{\text {max }}$ indicate high correlation coefficients and low RMSEs. This makes these equations well suited for the estimation of clearness index. The percentage errors are all within the accepted range of $-10 \%$ $10 \%$. This study proposes Equation 6 for Durban and this model's performance is depicted in Figure 13. The sunshine data was not measured from May
2010 to Jun 2018, due to technical limitations at the ARC, so this period was excluded from the analysis. The shape of the data shown in Figure 13 suggests that the model adequately estimates $K_{T}$ for the period available. Since fewer data points were analysed, this also had an impact on the error indicators reported in Table 7 .

Table 8: Proposed multivariate equations.

\begin{tabular}{l}
\hline No. \\
\hline $1 \frac{H}{H_{o}}=-0.029(\Delta T)+0.618\left(\frac{R H}{100}\right)+0.3135\left(\frac{S}{S_{o}}\right)+0.178$ \\
$2 \frac{H}{H_{o}}=-0.232(\sqrt{\Delta T})+0.460\left(\frac{R H}{100}\right)+0.624\left(\frac{S}{S_{o}}\right)-0.581$ \\
$3 \frac{H}{H_{o}}=0.045\left(T_{\max }\right)+0.474\left(\frac{R H}{100}\right)+0.159\left(\frac{S}{S_{o}}\right)-0.887$ \\
$4 \frac{H}{H_{o}}=0.433\left(\sqrt{T_{\max }}\right)+0.453\left(\frac{R H}{100}\right)+0.169\left(\frac{S}{S_{o}}\right)-1.936$ \\
$5 \frac{H}{H_{o}}=1.9 \times 10^{-3}(\Delta T)^{2}-0.110(\Delta T)-1.304\left(\frac{R H}{100}\right)^{2}+1.677\left(\frac{R H}{100}\right)+1.044\left(\frac{S}{S_{o}}\right)^{2}-0.982\left(\frac{S}{S_{o}}\right)+1.026$ \\
$6 \frac{H}{H_{o}}=-1.8 \times 10^{-3}\left(T_{\max }\right)^{2}+0.131\left(T_{\max }\right)-1.154\left(\frac{R H}{100}\right)^{2}+1.757\left(\frac{R H}{100}\right)-0.4735\left(\frac{S}{S_{o}}\right)^{2}+0.811\left(\frac{S}{S_{o}}\right)-2.436$ \\
$7 \frac{H}{H_{o}}=6.7 \times 10^{-4}(\Delta T)^{3}-0.04(\Delta T)^{2}+0.615(\Delta T)-25.6\left(\frac{R H}{100}\right)^{3}+47.02\left(\frac{R H}{100}\right)^{2}-28.5\left(\frac{R H}{100}\right)-2.57\left(\frac{S}{S_{o}}\right)^{3}-1.85\left(\frac{S}{S_{o}}\right)^{2}-0.49\left(\frac{S}{S_{o}}\right)+3.83$ \\
$8 \frac{H}{H_{o}}=7.5 \times 10^{-4}\left(T_{\max }\right)^{3}-0.06\left(T_{\max }\right)^{2}-1.27\left(T_{\max }\right)-6.143\left(\frac{R H}{100}\right)^{3}+11.25\left(\frac{R H}{100}\right)^{2}-6.43\left(\frac{R H}{100}\right)-18.59\left(\frac{S}{S_{o}}\right)^{3}+36.74\left(\frac{S}{S_{o}}\right)^{2}-23.7\left(\frac{S}{S_{o}}\right)+15.8$ \\
\hline $\begin{array}{l}\text { No. }=\text { number, } \frac{H}{H_{o}}=\text { extra-terrestrial radiation-global solar radiation ratio, RH }=\text { relative humidity, } \mathrm{T}_{\max }=\text { maximum temperature, } \frac{S}{S_{0}}= \\
\text { relative sunshine duration, } \Delta T=\text { temperature difference. }\end{array}$
\end{tabular}


Table 9: Error indicators for proposed equations.

\begin{tabular}{cccccccc}
\hline Equation & $R M S E$ & $M B E$ & $M A B E$ & $M P E$ & $M A P E$ & $M A R E$ & $R 2$ \\
\hline 1 & 0.25244 & 0.15038 & 0.19397 & 17.47650 & 30.41315 & 0.30413 & 0.19989 \\
2 & 0.24853 & 0.14751 & 0.19093 & 16.9053 & 29.76287 & 029763 & 0.8602 \\
3 & 0.14144 & $-4 \times 10^{-9}$ & 0.10475 & -5.08111 & 19.6809 & 0.19368 & 0.94689 \\
4 & 0.14166 & 0.01584 & 0.10686 & -1.73778 & 19.44057 & 0.19441 & 0.94672 \\
5 & 0.39480 & 0.34215 & 0.34764 & 14.63490 & 31.40490 & 0.31405 & 0.20488 \\
6 & 0.13838 & $6.41 \times 10^{-16}$ & 0.10853 & -4.58710 & 20.46811 & 0.20468 & 0.94916 \\
7 & 0.18301 & $-2.1 \times 10^{-15}$ & 0.15512 & -10.94380 & 30.67616 & 0.30676 & 0.33782 \\
8 & 0.11753 & $-1 \times 10^{-14}$ & 0.09414 & -3.16928 & 16.61409 & 0.16614 & 0.96333 \\
\hline
\end{tabular}

$\mathrm{RMSE}=$ root mean square error, $\mathrm{MBE}=$ mean bias error, $\mathrm{MABE}=$ mean absolute bias error, $\mathrm{MPE}=$ mean percentage error, $\mathrm{MAPE}=$ mean absolute percentage error, $\mathrm{MARE}=$ mean absolute relative error, $\mathrm{R}^{2}=$ coefficient of determination.

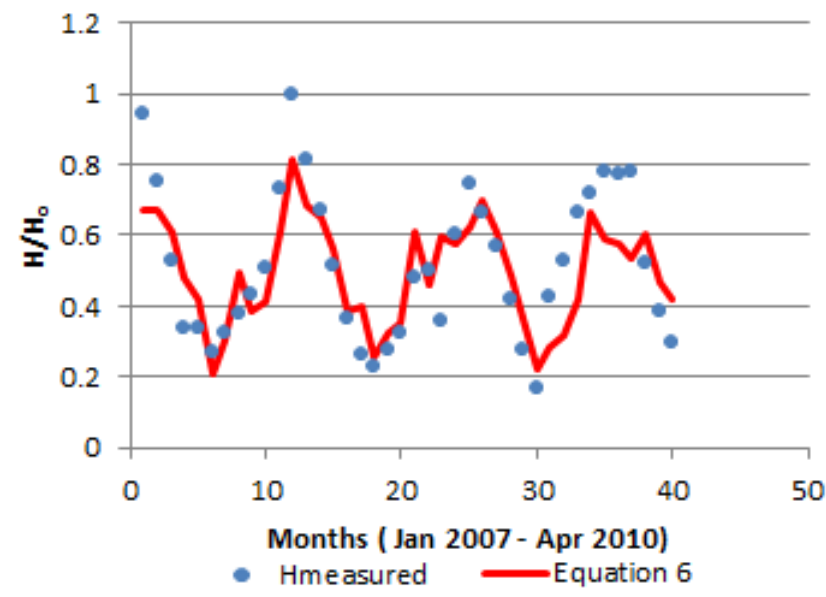

Figure 13: Proposed multivariate model using $T_{\max }$ to estimate $\frac{H}{H_{o}}$ for Durban, where $T_{\max }$, Hmeasured and $\frac{H}{H_{o}}$ represent the maximum temperature, observed values of global solar radiation and the extra-terrestrial radiationglobal solar radiation ratio respectively.

Error analysis for the proposed equations for Johannesburg shows low RMSE and MBE values, which make the above equations suitable. It is evident that $T_{\max }$ equations have a stronger dependency to clearness index values. Equation 8, which is a cubic function of $T_{\max }$, is proposed for Johannesburg and illustrated in Figure 14. The proposed model accurately fitted the historic data, with a high correlation coefficient and low error indicators and there were a few underestimations which may have resulted from the effects of any of the three variables included in the equation.

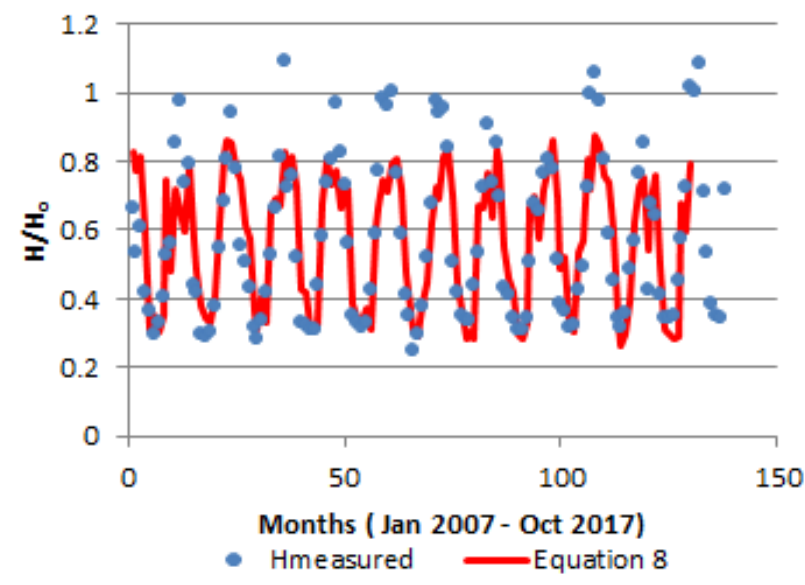

Figure 14: Proposed multivariate model using $\mathrm{T}_{\max }$ to estimate $\frac{H}{H_{o}}$ for Johannesburg, where $\mathrm{T}_{\text {max }}$, Hmeasured and $\frac{H}{H_{o}}$ represent the maximum temperature, observed values of global solar radiation and the extra-terrestrial radiationglobal solar radiation ratio respectively. 
Table 10: Proposed multivariate equations.

\begin{tabular}{|c|c|}
\hline No. & Equation \\
\hline & $\frac{H}{H_{o}}=0.048(\Delta T)+2.633\left(\frac{R H}{100}\right)+.174\left(\frac{S}{S_{o}}\right)-1.876$ \\
\hline & $\frac{H}{H_{o}}=0.310(\sqrt{\Delta T})+2.599\left(\frac{R H}{100}\right)+0.885\left(\frac{S}{S_{o}}\right)-2.361$ \\
\hline & $\frac{H}{H_{o}}=0.032\left(T_{\max }\right)+1.462\left(\frac{R H}{100}\right)+0.235\left(\frac{S}{S_{o}}\right)-1.390$ \\
\hline & $\frac{H}{H_{o}}=0.319\left(\sqrt{T_{\max }}\right)+1.463\left(\frac{R H}{100}\right)+0.231\left(\frac{S}{S_{o}}\right)-2.168$ \\
\hline & $\frac{H}{H_{o}}=-0.016(\Delta T)^{2}+0.475(\Delta T)+13.621\left(\frac{R H}{100}\right)^{2}-13.963\left(\frac{R H}{100}\right)+1.237\left(\frac{S}{S_{o}}\right)^{2}-1.612\left(\frac{S}{S_{o}}\right)+0.808$ \\
\hline & $\frac{H}{H_{o}}=0.002\left(T_{\max }\right)^{2}-0.085\left(T_{\max }\right)+7.513\left(\frac{R H}{100}\right)^{2}-8.183\left(\frac{R H}{100}\right)-0.910\left(\frac{S}{S_{o}}\right)^{2}-1.110\left(\frac{S}{S_{o}}\right)+3.533$ \\
\hline & $\frac{H}{H_{o}}=0.003(\Delta T)^{3}-0.12(\Delta T)^{2}+1.67(\Delta T)-9.02\left(\frac{R H}{100}\right)^{3}+31.06\left(\frac{R H}{100}\right)^{2}-25.38\left(\frac{R H}{100}\right)-8.77\left(\frac{S}{S_{o}}\right)^{3}+19.99\left(\frac{S}{S_{o}}\right)^{2}-14.53\left(\frac{S}{S_{o}}\right)+2.0$ \\
\hline & $\frac{H}{H_{o}}=8.9 \times 10^{-5}\left(T_{\max }\right)^{3}-0.004\left(T_{\max }\right)^{2}+0.047\left(T_{\max }\right)-22.51\left(\frac{R H}{100}\right)^{3}+50.56\left(\frac{R H}{100}\right)^{2}-35.24\left(\frac{R H}{100}\right)-9.17\left(\frac{S}{S_{o}}\right)^{3}+20.59\left(\frac{S}{S_{o}}\right)^{2}-14.7\left(\frac{S}{S_{o}}\right)+11.3$ \\
\hline & $\begin{array}{l}\text { number, } \frac{H}{H_{o}}=\text { extra-terrestrial radiation-global solar radiation ratio, } \mathrm{RH}=\text { relative humidity, } \mathrm{T}_{\max }=\text { maximum temperature, } \\
\text { lative sunshine duration, } \Delta T=\text { temperature difference. }\end{array}$ \\
\hline
\end{tabular}

Table 11: Error indicators for proposed equations.

\begin{tabular}{cccccccc}
\hline Equation & $R M S E$ & $M B E$ & $M A B E$ & $M P E$ & $M A P E$ & $M A R E$ & $R^{2}$ \\
\hline 1 & 0.13726 & $-6.6 \times 10^{-16}$ & 0.11001 & -6.71925 & 25.21744 & 0.25217 & 0.59623 \\
2 & 0.13758 & $-9.6 \times 10^{-16}$ & 0.11045 & -6.79374 & 25.39489 & 0.25395 & 0.93908 \\
3 & 0.12468 & $-1.3 \times 10^{-16}$ & 0.10076 & -5.39414 & 22.82711 & 0.22827 & 0.94996 \\
4 & 0.12490 & $9.4 \times 10^{-17}$ & 0.10090 & -5.39830 & 22.89302 & 0.22893 & 0.94979 \\
5 & 0.18160 & 0.14 & 0.14929 & -20.75960 & 28.27592 & 0.28276 & 0.29317 \\
6 & 0.11116 & $1.44 \times 10^{-15}$ & 0.08474 & -4.43616 & 17.83656 & 0.17837 & 0.96023 \\
7 & 0.11077 & $9.7 \times 10^{-15}$ & 0.08462 & -4.43619 & 17.68162 & 0.17682 & 0.73701 \\
8 & 0.10744 & $2.4 \times 10^{-15}$ & 0.08199 & -4.22186 & 17.64309 & 0.17643 & 0.96285 \\
\hline
\end{tabular}

$\mathrm{RMSE}=$ root mean square error, $\mathrm{MBE}=$ mean bias error, $\mathrm{MABE}=$ mean absolute bias error, $\mathrm{MPE}=$ mean percentage error, $\mathrm{MAPE}=$ mean absolute percentage error, $\mathrm{MARE}=$ mean absolute relative error, $\mathrm{R}^{2}=$ coefficient of determination.

First order equations using $\sqrt{\Delta T}, T_{\max }$ and $\sqrt{T_{\max }}$ indicate high $R^{2}$ values with low error indicators shown in Table 11. Equations containing $T_{\max }$ again show a stronger relationship to $K_{T}$ values. For Pietermaritzburg, Equation 6 is proposed. The model's efficiency is depicted in Figure 15 and indicates a well-suited model. Sunshine duration data was unavailable for certain months as a result of technical limitations from the data source and hence the analysis was completed only for the period 2007-2014.

The above analysis is evidence that non-linear, multivariate models are more efficient in estimating GSR than linear, single variable models. Strong $\mathrm{R}^{2}$ coefficients are detailed for the proposed multivariate equations. Low error indicators (RMSE, MBE and MPE) describe the suitability of these models for
GSR prediction over the long-term. The MAPE error values can be explained by the rounding and averaging of hourly and daily recordings to obtain monthly average values. It was found that the dependence of $\frac{H}{H_{o}}$ on $T_{\max }$ is stronger than that of $\Delta T$ (derived from the H-S model), while relative sunshine duration $\frac{S}{S_{o}}$ is a strong indicator of the GSR experienced across the study sites. Higher order equations (both single and multivariate relationships) prove to be more accurate. The equations suggested for the five study sites demonstrate their suitability for the estimation of GSR over the long term, i.e., forecasting, horizon and are summarised in Table 12. 


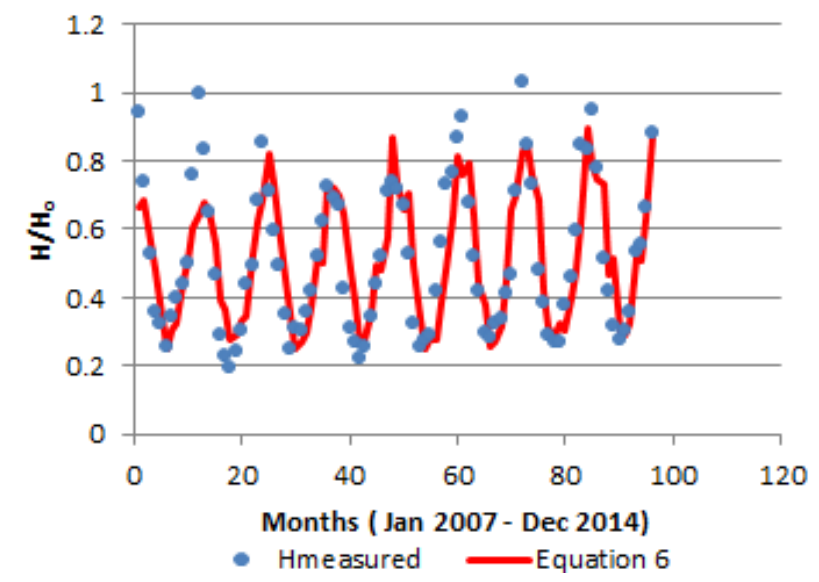

Figure 15: Proposed multivariate model using $T_{\max }$ to estimate $\frac{H}{H_{o}}$ for Pietermaritzburg, where $T_{\max }$, Hmeasured and $\frac{H}{H_{o}}$ represent the maximum temperature, observed values of global solar radiation and the extra-terrestrial radiation-global solar radiation ratio respectively.

Table 12: Summary of multivariate equations for each study site.

\begin{tabular}{cl}
\hline Site & Equation \\
\hline BFN & $\frac{H}{H_{o}}=0.040\left(T_{\max }\right)-0.307\left(\frac{R H}{100}\right)+1.151\left(\frac{S}{S_{o}}\right)-0.979$ \\
CT $\quad \frac{H}{H_{o}}=4 \times 10^{-4}\left(T_{\max }\right)^{3}-0.03\left(T_{\max }\right)^{2}+0.71\left(T_{\max }\right)+13.33\left(\frac{R H}{100}\right)^{3}-19.66\left(\frac{R H}{100}\right)^{2}+7.52\left(\frac{R H}{100}\right)+2.25\left(\frac{S}{S_{o}}\right)^{3}-0.46\left(\frac{S}{S_{o}}\right)^{2}-0.368\left(\frac{S}{S_{o}}\right)-5.41$ \\
$\mathrm{DBN} \quad \frac{H}{H_{o}}=-1.4 \times 10^{-3}\left(T_{\max }\right)^{2}+0.108\left(T_{\max }\right)+13.097\left(\frac{R H}{100}\right)^{2}-16.833\left(\frac{R H}{100}\right)-1.180\left(\frac{S}{S_{o}}\right)^{2}+1.6025\left(\frac{S}{S_{o}}\right)+3.399$ \\
$\mathrm{JHB} \quad \frac{H}{H_{o}}=7.5 \times 10^{-4}\left(T_{\max }\right)^{3}-0.06\left(T_{\max }\right)^{2}-1.27\left(T_{\max }\right)-6.143\left(\frac{R H}{100}\right)^{3}+11.25\left(\frac{R H}{100}\right)^{2}-6.43\left(\frac{R H}{100}\right)-18.59\left(\frac{S}{S_{o}}\right)^{3}+36.74\left(\frac{S}{S_{o}}\right)^{2}-23.7\left(\frac{S}{S_{o}}\right)+15.8$ \\
PMB $\quad \frac{H}{H_{o}}=0.002\left(T_{\max }\right)^{2}-0.085\left(T_{\max }\right)+7.513\left(\frac{R H}{100}\right)^{2}-8.183\left(\frac{R H}{100}\right)-0.910\left(\frac{S}{S_{o}}\right)^{2}-1.110\left(\frac{S}{S_{o}}\right)+3.533$ \\
\hline BFN = Bloemfontein, CT $=$ Cape Town, DBN $=$ Durban, JHB $=$ Johannesburg, PMB $=$ Pietermaritzburg, $\frac{H}{H_{o}}=$ extra-terrestrial radiation- \\
global solar radiation ratio, RH = relative humidity, Tmax $=$ maximum temperature, $\frac{S}{S_{0}}=$ relative sunshine duration.
\end{tabular}

\section{Conclusions}

This study analysed the impact of single variable, linear estimation models on the available GSR within South Africa in comparison to multivariate, non-linear regression models which incorporate variations of meteorological parameters. The investigation to propose linear and non-linear analysis of multivariate models for the estimation of global solar radiation (GSR) received across five South African cities indicated that the empirical Hargreaves-Samani and Angstrom-Prescott models proved to be reliable methods for estimating the amount of GSR in shorter study periods (i.e., one calendar year), but lacked accuracy for long-term estimations. This work further indicated that models that make use of a single meteorological variable and most linear models are not able to adequately predict GSR for the selected cities over periods longer than ten calendar years. Meteorological parameters used for this research were substantially easy to obtain, except for sunshine data measurements that are not always available because of the costly equipment they demand. This study provided insights on the estimation of GSR in South Africa, which can be accurate, easily employed, and subsequently cost-effective. The proposed models are unique to each of the selected cities and may be incorporated into the design and installation processes of solar photovoltaic (PV) technologies to enhance their efficiency, while endorsing their application. Furthermore, the proposed economical models are appropriate for the feasibility study of solar PV technologies in South Africa. 


\section{Acknowledgements}

The assistance of the Agricultural Research Council and South African Weather Service to collate relevant data for this study is acknowledged.

\section{Author roles}

Tamara Rosemary Govindasamy: project initiator, research formulation, data collection, write-up, analytical techniques and implementation

Naven Chetty: research formulation, project supervision, technical advice, write-up input plus analysis techniques and processing

\section{References}

[1] Department of Minerals and Energy. 2003. White Paper on Renewable Energy. Available from: https://unfccc.int/files/meetings/seminar/application/pdf/sem_sup1_south_africa.pdf

[2] Dlamini M. D., Varkey A. J., Mkhonta S. K. 2017. Models for calculating monthly average solar radiation from air temperature in Swaziland. International Journal of Physical Sciences 12: 247-254. DOI: https://doi.org/10.5897/IJPS2017.4679

[3] Maleki S. A. M., Hizam H., Gomes C. 2017. Estimation of hourly, daily and monthly global solar radiation on inclined surfaces: Models re-visited. Energies 10(1), 134. DOI: https://doi.org/10.3390/en10010134

[4] Zhandire E. 2017. Predicting clear-sky global horizontal irradiance at eight locations in South Africa using four models. Journal of Energy in Southern Africa, 28 (4): 77-86. DOI: https://dx.doi.org/10.17159/24133051/2017/v28i4a2397.

[5] Da Silva V. J., Da Silva C. R., Almorox J., Junior J. A. 2016. Temperature based solar radiation models for use in simulated soybean potential yield. Australian Journal of Crop Science, 10 (7): 926-932. DOI: https://dx.doi.org/10.21475/ajcs.2016.10.07.p7301

[6] Falayi E.O., Rabiu A.B. 2012. Solar radiation models and information for renewable energy applications. Solar radiation, E. B. Babatunde, IntechOpen. 111-130. DOI: https://doi.org/10.5772/35390.

[7] Fu Q. 2003. Radiation (solar). University of Washington, Seattle, WA. USA. Elsevier. 1859-1863.

[8] Meenal R., Boazina P. G., Selvakumar A. I. 2016. Temperature based radiation models for the estimation of global solar radiation at horizontal surface in India. Indian Journal of Science and Technology, 9(46). DOI: http://dx.doi.org/10.17485/ijst\%2F2016\%2Fv9i46\%2F101922.

[9] Samani Z. 2000. Estimating solar radiation and evapotranspiration using minimum climatological data. Journal of Irrigation and Drainage Engineering, ASCE 126(4): 265-267.

[10] Allen R.G. 1991. Self-calibrating method for estimating global solar radiation from air temperature. Journal of Hydrologic Engineering, New York, 2:56-57.

[11] Hargreaves G. H., Samani Z. A. 1982. Estimating potential evapotranspiration. Journal of Irrigation and Drainage Engineering, ASCE, 108(IR3):223-230.

[12] Almorox J., Bocco M. Wellington E. 2013. Estimation of daily global solar radiation from measured temperatures at Canada de Luque, Corboda, Argentina. Renewable Energy, 60(C): 382-387.

[13] Dlamini M. D., Varkey A. J., Mkhonta S. K. 2017. Models for calculating monthly average solar radiation from air temperature in Swaziland. International Journal of Physical Sciences, 12: 247-254.

[14] Sarkar N.I., Sifat A. I., Paul S., Hossain S., Rahman M. 2016. Solar radiation estimation using temperature data for Dhaka, Bangladesh. Proceedings of the 5th International Conference on Informatics, Electronics and Vision (ICIEV), Dhaka, 2016: 204-208. DOI: https://dx.doi.org/10.1109/ICIEV.2016.7759996

[15] Almorox J., Hontoria C., Benito M. 2011. Models for obtaining daily global solar radiation with measured air temperature data in Madrid (Spain). Applied Energy, 88:1703-1709.

[16] Renewable energy scenarios for municipalities in South Africa. January 2018. South African Local Government Association: Opportunities in renewable energy and energy efficiency for municipalities in South Africa.

[17] Musango J. K., Amigun B., Brent A. C. 2011. Sustainable electricity generation technologies in South Africa: Initiatives, challenges and policy implications. Energy and Environment Research, 1 (1): 124-138. DOI: https://dx.doi.org/10.5539/eer.v1n1p124

[18] S.K. Solanki and M. Fligge. 1998. Solar irradiance since 1874 revisited. Geophysical Research Letters, 25(3): 341-344.

[19] Sayigh A. A. M. 1977. Solar radiation availability prediction from climatological data. Journal of Solar Energy Engineering, -1: 61-82.

DOI: https://dx.doi.org/10.1016/B978-0-12-620850-4.50010-7

[20] Viorel B (Ed). 2008. Modeling solar radiation at the earth's surface: Recent advances. Springer, Germany. Chapter 1.

[21] Campbell G. S., John M. N. 1998. An introduction to environmental biophysics. $2^{\text {nd }}$ Ed. Springer, New York.

[22] Tijjani B.I. 2017. Comparison between first and second order Angstrom type models for sunshine hours in Katsina Nigeria. Bayero. Journal of Pure and Applied sciences, 4(2): 24-27. DOI: http://dx.doi.org/10.4314/bajopas.v4i2.5 
[23] Ituen Eno E., Esen Nisken U., Nwokolo Samuel C., Uto Ema G. 2012. Prediction of Global solar radiation using relative humidity, maximum temperature and sunshine hours in Uyo in the Niger Delta Region, Nigeria. Advances in Applied Science Research, 3(4): 1923-1937.

[24] Meinel A. B., Meinel M. P. 1976. Applied solar energy. An introduction. Chapter 8. Addison-Wesley, Michigan.

[25] Academy of Science of South Africa. 2014. The state of energy research in South Africa. ASSAF, Pretoria.

[26] Sendanayake S. Miguntanna N. P., Jayasinghe M. T. R. 2014. Estimating incident solar radiation in tropical islands with short term weather data. European Scientific Journal,10 (3): 40-412 DOI: http://dx.doi.org/10.19044/esj.2014.v10n3p\%25p.

[27] Prescott J. A. 1940. Evaporation from water surface in relation to solar radiation. Transactions of the Royal Society of Australia, 46: 114-118.

[28] Angstrom A. 1924. Solar and atmospheric radiation. Report to the International commission for solar research on actinometric investigations of solar and atmospheric radiation. Journal of the Royal Meteorological Society: 121126. DOI: https://doi.org/10.1002/qj.49705021008.

[29] Teke A., Yilidirim H. B. 2014. Estimating the monthly global solar radiation for Eastern Mediterranean Region. Energy Conversion and Management, 87: 628-635.

[30] Günther M., Janotte N., Mezrhab A., Pottler K., Schillings C., Wilbert S. and Wolferstätter F. 2011, Advanced CSP Teaching Materials, Solar Radiation. Adv CSP Teach, Mater, Enermena. Chapter 2: 7-82.

[31] Srivastava R. C., Pandey H. 2013. Estimating Angstrom-Prescott coefficients for India and developing a correlation between sunshine hours and global solar radiation for India. ISRN Renewable Energy, (2013). DOI: http://dx.doi.org/10.1155/2013/403742.

[32] Allen R. G., Pereira L. S., Raes D., Smith M. 1998. Crop evapotranspiration (Guidelines for computing crop water requirements). Food and Agriculture Organization of the United Nations, Irrigation and drainage paper no. 56, Rome. European Environment Agency. Available from: http://www.fao.org/docrep/x0490e/x0490e00.htm

[33] Sarkar M. N. I., Sifat A. I. 2016. Global solar radiation estimation from commonly available meteorological data for Bangladesh. Renewables 3(6). DOI: https://doi.org/10.1186/s40807-016-0027-3.

[34] Marwal V.K., Punia R.C., Sengar N., Mahawar S., Dashora P. 2012. A comparative study of correlation functions for estimation of monthly mean daily global solar radiation for Jaipur, Rajasthan (India), Indian Journal of Science and Technology, 5(5): 2729-2732.

[35] Robaa S.M. 2008. Evaluation of sunshine duration from cloud data in Egypt. Energy, 33(5): 789-795.

[36] Adeala A. A., Huan Z., Enweremadu C. C. 2015. Evaluation of solar radiation using multiple weather parameters as predictors for South Africa provinces. Thermal Science, 19 (2): 495-509.

[37] Ya'u M. J., Gele M. A., Ali Y. Y., Alhaji M. 2018. Global solar radiation models: A review. Journal of Photonic Materials and Technology, 4(1): 26-32.

[38] Itodo I. N., Yohanna J. K. 2011. Correlation between global solar radiation, ambient air temperature and sunshine hours for Makurdi, Nigeria. Proceedings of the Solar World Congress, Solar Radiation Availability and Variability. 2011. DOI: https://dx.doi.org/10.18086/swc.2011.24.17

[39] Nia M., Chegaar M., Benatallah M. F., Aillerie M. 2013. Contribution to the quantification of solar radiation in Algeria. Energy Procedia, 36: 730-737.

[40] van den Besselaar E. J. M., Sanchez-Lorenzo A., Wild M., Tank A. M. G. K., de Laat A. T. J. 2015. Relationship between sunshine duration and temperature trends across Europe since the second half of the $20^{\text {th }}$ century. Journal of Geophysical Research: Atmospheres, 120 (20): 10 823-10 836. DOI: https://doi.org/10.1002/2015JD023640.

[41] Chen J.L., Li G.S. 2013. Estimation of monthly average daily solar radiaton from measured meteorological data in Yangtze River Basin in China. International Journal of Climatology, 33: 487-498.

[42] Rivington M., Bellocchi G., Matthews K. B., Buchan K. 2005. Evaluation of three model estimations of solar radiation at 24 UK stations. Agricultural and Forest Meteorology, 132: 228-243.

[43] Jury M. R. 2013. Climate trends in southern Africa. South African Journal of Science, 109 (1-2): 1-11. DOI: http://dx.doi.org/10.1590/sajs.2013/980.

[44] Burton M., Cooke S., Godfrey A., Neville L., Pauker E., Le Roux-Rutledge E. 2010. Africa talks climate: The public understanding of climate change in ten countries. Executive Summary. BBC World Service Trust, London, UK, 20.

[45] South Africa climate and weather by regions. Available from: http://www.cosechaypostcosecha.org/data/articulos/ConvenioSudafrica/ClimateAndWeather.pdf. 